\title{
DIFFERENCES IN FORAGING AND VIGILANCE BETWEEN JUVENILE AND PARENT SANDHILL CRANES DURING FALL MIGRATION
}

\author{
JARED B. CLARKE, 323 Habkirk Drive, Regina SK S4S 6A9. \\ E-mail:clarkejared16@yahoo.ca
}

\section{Introduction}

Prey organisms face a trade-off between maximizing food intake, while having to watch for predators..$^{2,7,11}$ If an organism focuses too much on one aspect of this trade off then its chances of either starving or being depredated are increased. This trade off appears to be most critical for juveniles. In many bird species, juveniles tend to have poorer foraging ability than adults. ${ }^{4}$ This leaves juveniles at a disadvantage, because they must spend more time foraging than adults and less time being vigilant to avoid predators, ultimately increasing their chance of being depredated.

Some species remain in a family group to help counter this disadvantage. It is thought many geese and crane species, including Sandhill Cranes, remain in family groups for this reason. ${ }^{3,5}$ In the family group, juveniles are able to spend more time foraging while their own vigilance time can be decreased. The length of time the family group remains together varies among species, but is terminated once the cost to individuals, either adult or juvenile, outweighs the benefits. ${ }^{10}$

Sandhill Cranes are a migratory species that nests mainly in boreal and arctic Canada and Alaska. The cranes winter in the southern United States and Mexico. The Last Mountain Lake
National Wildlife Area and Migratory Bird Sanctuary in Saskatchewan, is a major migratory stopover point for this species. Sandhill Cranes have a clutch size of one or two eggs, therefore family groups consist of three to four individuals. Once cranes leave the breeding ground, the young appear to have flying abilities equivalent to those of adults. ${ }^{10}$ The family group migrates together in fall and remains in a group up until spring migration. ${ }^{9}$ Human hunters are the primary predator faced by Sandhill Cranes during fall migration.

The purpose of my study was to compare Sandhill Crane parent and juvenile foraging and vigilance times at a fall migration stopover point. If young cranes are dependent on adults for protection while foraging at this point in their migration, I predicted that the vigilance times for juveniles would be lower than for their parents. Another purpose of this study was to determine whether distance of a family group from the flock influenced the vigilance and foraging times of juveniles and adults in the family group differently. I predicted that for adults, vigilance time should increase as the family group gets farther from the flock. If the vigilance times differ between adult and juveniles significantly, I predicted that distance would not affect the juveniles' vigilance. 


\section{Methods}

From 28 - 31 August 2006, I observed Sandhill Cranes as they foraged in a barley lure crop approximately $1 \mathrm{~km}$ east of the Last Mountain Lake Migratory Bird Sanctuary $\left(51^{\circ} 23.780 \mathrm{~N}, 1^{\circ}\right.$ $09.723 \mathrm{~W})$. The field was approximately $4 \mathrm{~km}^{2}$ subdivided by five rows of Caragana (Caragana arborescens) shrubs that ran east to west. Because of the obstruction created by the shrubs, I changed my observation point daily so that I could view cranes on all portions of the field. Observations were made daily between $0900 \mathrm{~h}$ and $1100 \mathrm{~h}$, and 1800h and 1930h. I used a $25-45$ x $60 \mathrm{~mm}$ Nikon spotting scope and was usually able to get within $400 \mathrm{~m}$ of the flock to make observations.

Total flock size varied from approximately 1,500 to 3,000 individuals during the study period. Approximately $5-10 \%$ of the birds were juveniles. Adults and juveniles were differentiated on the basis of plumage. ${ }^{6}$ Adult Sandhill Cranes have a distinct red cap that extends from the bill to the back of the head, as well as a white cheek patch. Juveniles lack both of these characteristics and have a uniformly grey head. I identified family groups after watching which adult birds moved with which juvenile(s), a process which took between 1 to 20 min. per juvenile. I selected family groups from different areas in the field to prevent counting a particular group twice. Once selected, a family group was assigned a designation based on its distance to the next group: In flock (0 $\mathrm{m}$ from flock), Near flock ( $<10 \mathrm{~m}$ from flock), and Distant (>10 m from flock). A flock was defined as $10+$ birds with $<2 \mathrm{~m}$ between adjacent birds.

One juvenile crane from each family group was observed for $2 \mathrm{~min}$ as it foraged. I assumed that when birds were at the lure crop their main focus was foraging. I recorded both the number of head lifts (head raised above shoulder level) and the amount of time the bird's head remained lifted. On a small number of occasions, birds lifted their heads and began preening without looking around. I did not count preening as a head lift. Immediately after observing the juvenile, I recorded the same data for one of the adults of the family group for 2 minutes. I terminated observations if all cranes in the immediate area or entire field lifted their heads after a bird gave a warning call. This usually occurred when vehicles passed along the road adjacent to the field. Overall, I sampled 26 pairs of juveniles and adults during the study period.

To compare the number of head lifts and the length of time spent watching by juveniles versus parents I used a paired t-test. ${ }^{12}$ This controlled for the distance variable from other birds. I then used a one factor ANOVA to asses the difference between the number of head lifts and time spent with head lifted for each of the three categories of distance of the family group from the flock. For both tests I employed an alpha value of 0.05 .

\section{Results}

Of the 26 pairs of juvenile and adult birds I observed, I found that adults lifted their heads significantly more often $(t=4.3, d f=25, p<0.01)$ than juveniles (Fig. 1). The number of head lifts for juveniles ranged from $0-4$, while adults made 1 - 6 head lifts during the 2 min period. Adult cranes also kept their heads up for significantly longer than juveniles $(t=1999.3, d f=25, p$ $<0.01$; Fig. 2). The range for the total time juvenile cranes kept their heads raised during the two minutes, was 0 to $28 \mathrm{sec}$, while for adults the total time ranged from 1 to 44 sec. 


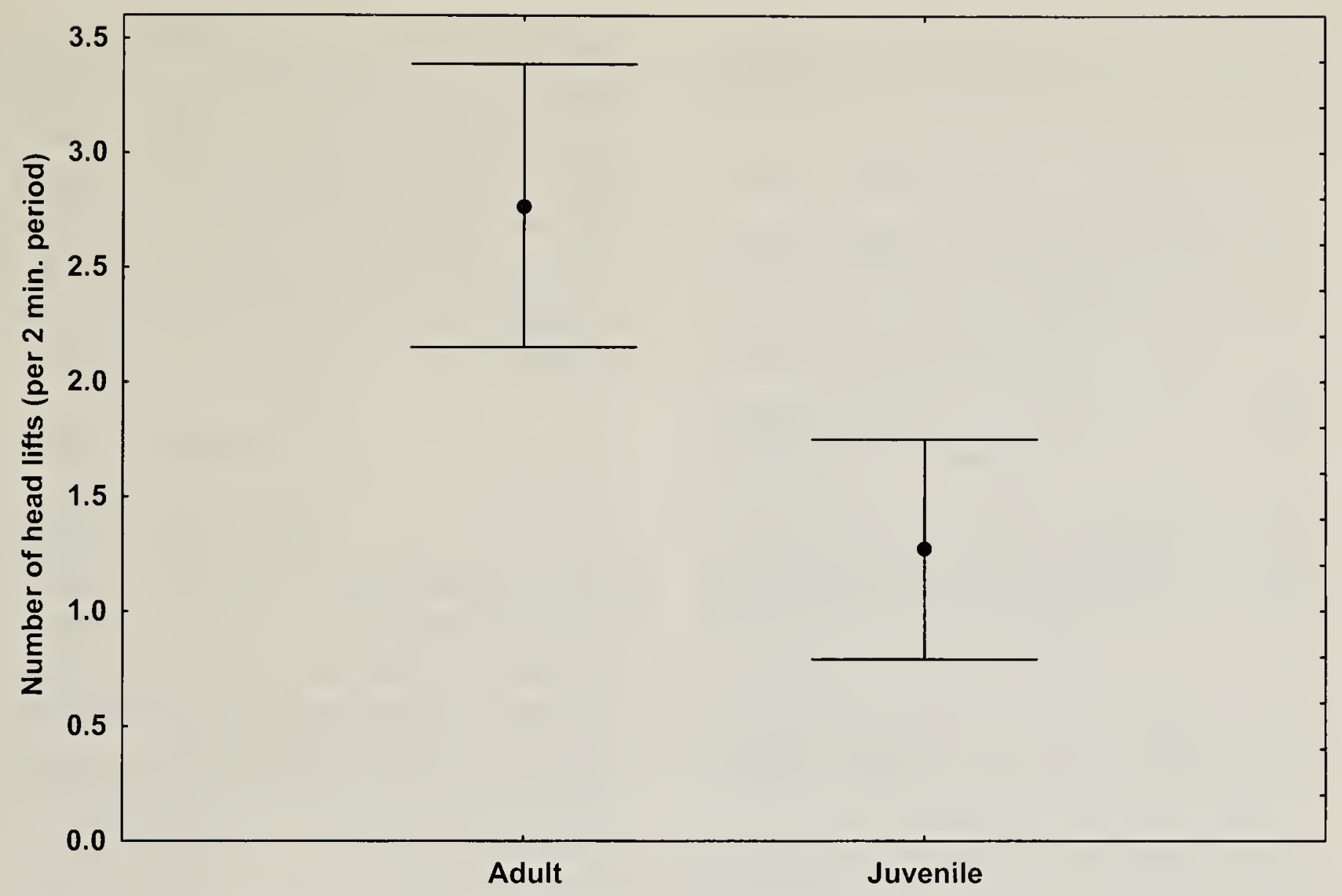

Figure 1. Mean number of head lifts between adult and juvenile Sandhill Cranes during 2 min observation periods. 95\% confidence interval shown.

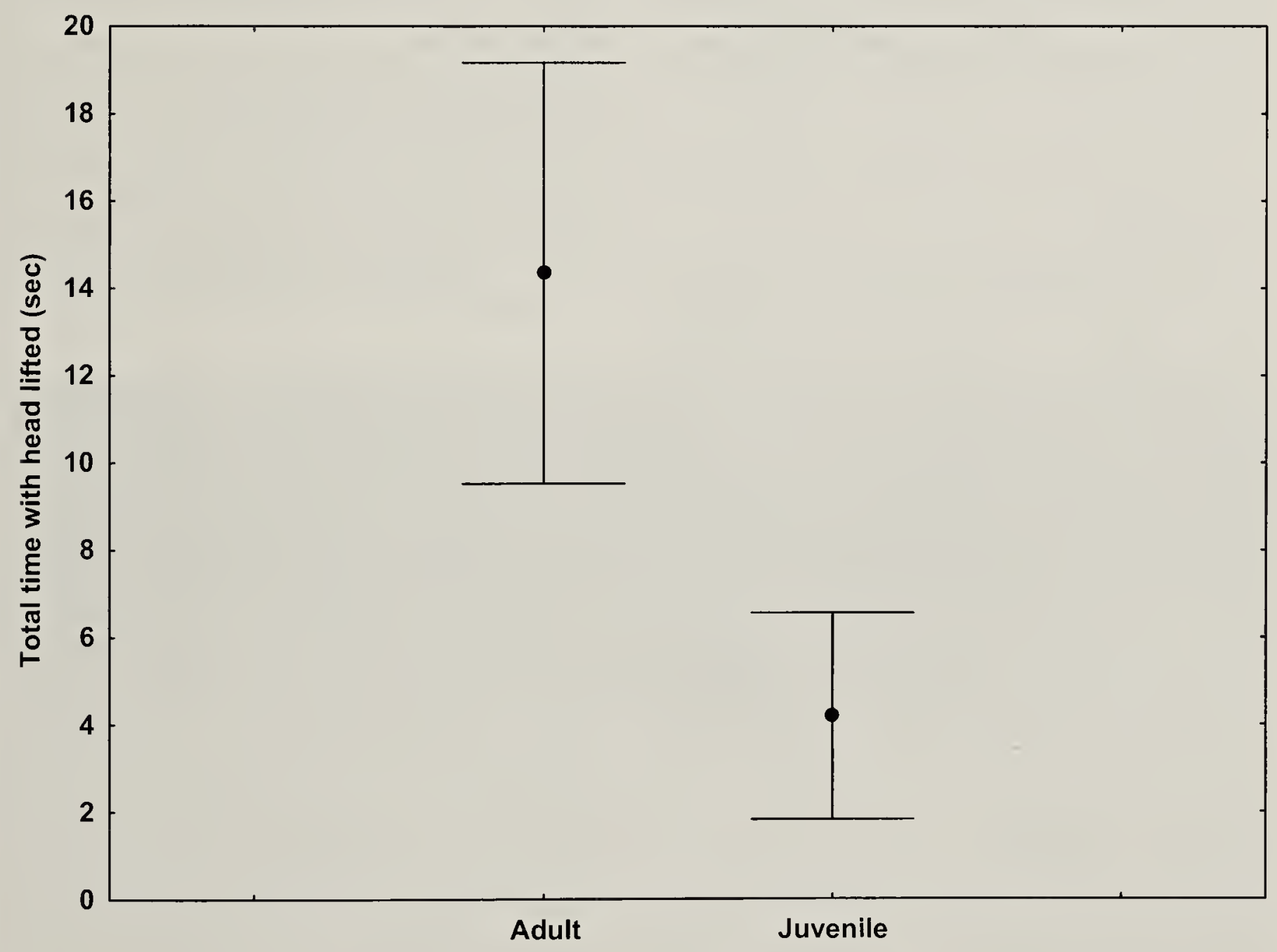

Figure 2. Mean total time spent with head raised during 2 min observation periods between the adult and juvenile Sandhill Cranes. 95\% confidence interval shown. 
There was no statistically significant difference in the number of head lifts made by juveniles at the three relative distances from a flock $(F=3.4, d f=2$, $p=0.82)$. The average number of head lifts for juveniles during the two minute period at varying distances from the flock-In flock, Near flock and Distantwere 1.2, 1.5, and 1.1 respectively. There was also no statistically significant effect of distance on the total time juveniles spent with their heads lifted $(F=3.44, d f=2, p=0.3)$. Average total amount of time spent with head lifted for juveniles In flock, Near flock and Distant, were 4.4, 7.2, and 2.3 seconds respectively. For adult cranes, neither the number of head lifts $(F=3.44, d f=2$, $p=0.81)$, nor the total time with head lifted $(F=3.44, d f=2, p=0.37)$ differed significantly as a function of distance from the flock. The average number of head lifts for adult cranes In flock, Near flock and Distant, were 2.7, 2.5, 3.0, respectively, while total time spent with head lifted at these same distances was $10.0,14.5$, and 18.1 seconds, respectively.

\section{Discussion}

I found that adult Sandhill Cranes spent more time being vigilant (with their heads raised, presumably watching for predators) than did juvenile cranes; this difference was statistically significant. My data support the hypothesis that young cranes rely on vigilance by adults in a family group during this point in fall migration.

A family group has many potential benefits for juvenile cranes. Firstly, the family group system allows the juveniles to allocate more of their time to foraging, instead of watching for predators. This extra foraging time allows the juveniles to compensate for the discrepancy of foraging abilities between themselves and their parents. Family groups also protect juveniles from agonistic encounters from more dominant or aggressive cranes, which again allows for more feeding time. ${ }^{9}$ Another important benefit of the family group is simply that there are more eyes watching for predators, which will increase the juvenile's chance of survival.

In another study, over the winter season, vigilance time of juvenile Common Cranes (Grus grus, a close relative of Sandhills) increased as their foraging abilities improved. ${ }^{1}$ The juveniles' vigilance times were close to equal to those of their parents, when the family group broke up. I would expect this trend to be similar in Sandhill Cranes.

There appears to be no obvious cost to adult Sandhill Cranes in being in a family group during the non-breeding season. ${ }^{10}$ Adult Common Cranes were able to spend significantly less time feeding than juveniles birds, while still having a higher net intake of food than the juveniles. ${ }^{1}$ This difference is the key reason why adult cranes, both Sandhill and Common, are able to maintain higher vigilance than juveniles and why the family group structure is beneficial.

I found no change in vigilance by either juvenile or adult birds at varying distances from the flock. The distribution of birds was not uniform over the field, which could have affected how the cranes perceived their position in the flock even though, from my observation point, they fell into certain distance categories. A possible limitation of my study was that three different distance variables assigned to the pairs of birds was too small. The sample sizes for this test were also relatively small.

\section{Conclusion}

The interactions between juvenile 
and adult Sandhill Cranes in family groups appear to be advantageous. This strategy allows the juveniles to forage maximally while relying on adults to detect predators. The family group system appears to be a good strategy to cope with the difficult tradeoff between foraging and vigilance that is forced on juveniles because of their poorer foraging ability.

\section{Acknowledgments}

Thank you to Mark Brigham and Kristen Bondo for their comments and suggestions during the early stages of this study and on this manuscript. I am appreciative of the helpful comments on the manuscript from Rick Espie, Tracy Fisher, C. Stuart Houston, and Trevor Herriot. Rick Espie also helped in the creation the graphs.

1. ALONSO, J.A., and J.C. ALONSO. 1993. Agerelated differences in time budgets and parental care in wintering common cranes. Auk 110: 7888.

2. BARBOSA, A. 1997. The effects of predation risk on scanning and flocking behaviour in Dunlin. Journal of Field Ornithology. 68: 607-612.

3. BLACK, J.M and M. OWEN. 1989. Parentoffspring relationships in wintering barnacle geese. Animal Behaviour 37: 187-198.
4. GOSS-CUSTARD, J.D. and S.E.A. le V. dit DURELL.1987. Age-related effects in oystercatchers Haematopus Ostralegus, feeding on mussels Mytilus Edulis. Journal of Animal Ecology 56: 549-558.

5. GREGOIRE, P.E. and C.D ANKNEY. 1990. Agonistic behaviour and dominance relationships among lesser snow geese during winter and spring migration. Auk 107: 550-560.

6. SIBLEY, D. 2000. The Sibley Guide to Birds. Knopf Publishing, New York.

7. SLOTOW, R. and E. PAXINOS. 1997. Intraspecific competition influences food returnpredation risk trade-off by White-crowned Sparrows. Condor 99: 642-650.

8. TACHA, T.C., C. JORGENSON and P.S. TAYLOR. 1985. Harvest, migration, and condition of Sandhill Cranes in Saskatchewan. Journal of Wildlife Management 49: 478-480.

9. TACHA, T.C. 1988. Social Organization of Sandhill Cranes from Mid-Continental North America. Wildlife Monographs 99.

10. TACHA, T.C., S.A NESBIT, and P.A. VOHS 1992. Sandhill Crane (Grus canadensis). In The Birds of North America, No. 31 (A. Poole, P. Stettenheim, and F. Gill, eds.). Philadelphia: The Academy of Natural Sciences; Washington, DC The American Ornithologist's Union.

11. WAITE, T.A. and T.C GRUBB JR. 1987. Dominance, foraging and predation risk in the Tufted Titmouse. Condor 89: 936-940.

12. ZAR, J.H. 1984. Biostatistical analysis, 2nd ed. Prentice-Hall International Editions, Upper Saddle River, New Jersey.

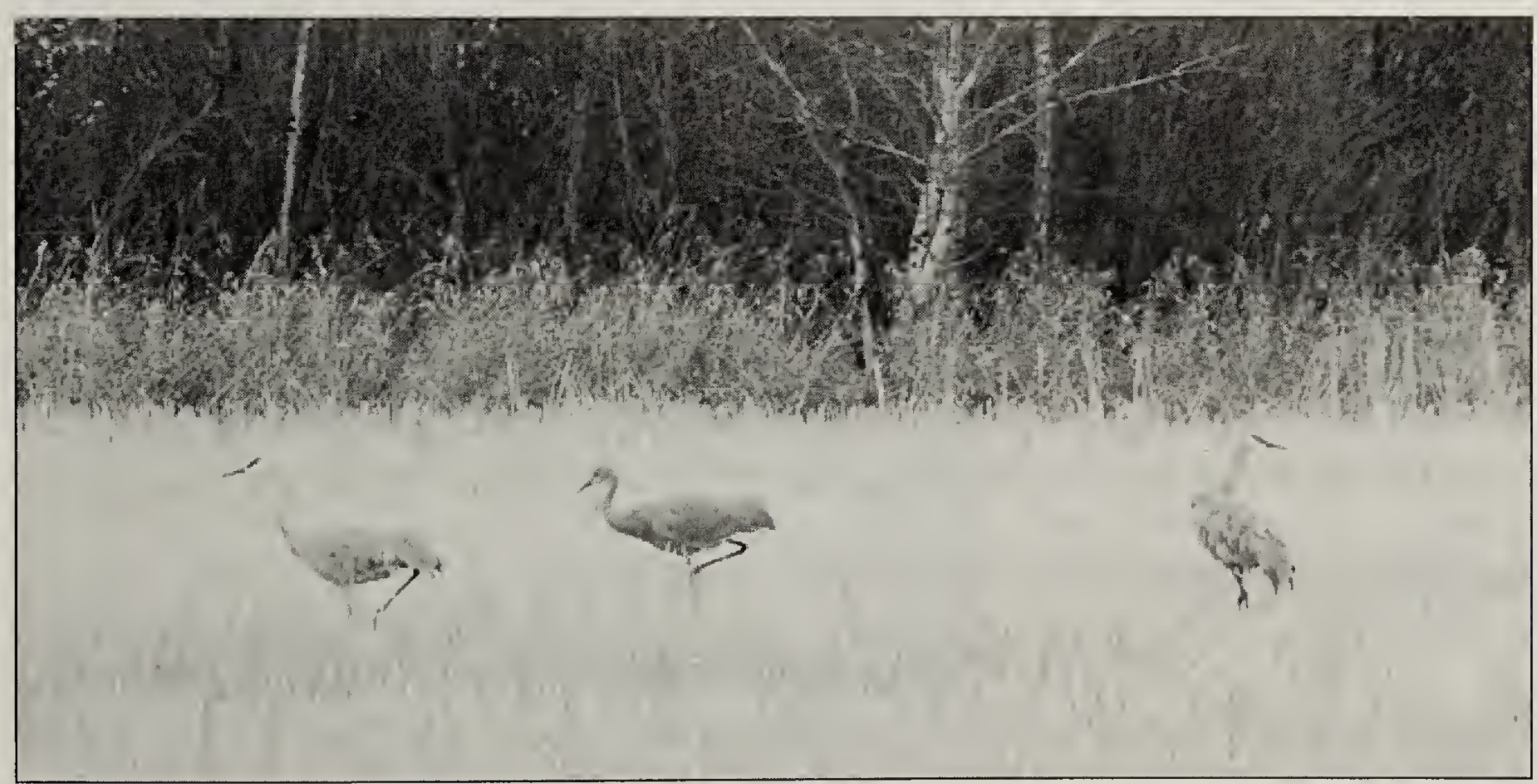

